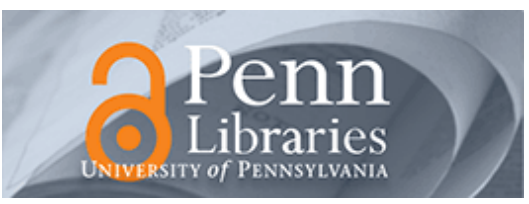

University of Pennsylvania

ScholarlyCommons

6-21-2004

\title{
LVAD as Destination Therapy - The Economic Dilemma
}

\author{
Pamela Douglas \\ University of Pennsylvania \\ Courtney Morgan \\ University of Pennsylvania \\ Heather Lee \\ University of Pennsylvania \\ Kenneth R. Foster \\ University of Pennsylvania, kfoster@seas.upenn.edu
}

Follow this and additional works at: https://repository.upenn.edu/be_papers

Part of the Biomedical Engineering and Bioengineering Commons

\section{Recommended Citation}

Douglas, P., Morgan, C., Lee, H., \& Foster, K. R. (2004). LVAD as Destination Therapy - The Economic Dilemma. Retrieved from https://repository.upenn.edu/be_papers/61

Copyright 2004 IEEE. Reprinted from IEEE Technology and Society Magazine, Volume 23, Issue 2, Summer 2004, pages 23-27.

This material is posted here with permission of the IEEE. Such permission of the IEEE does not in any way imply IEEE endorsement of any of the University of Pennsylvania's products or services. Internal or personal use of this material is permitted. However, permission to reprint/republish this material for advertising or promotional purposes or for creating new collective works for resale or redistribution must be obtained from the IEEE by writing to pubs-permissions@ieee.org. By choosing to view this document, you agree to all provisions of the copyright laws protecting it.

This paper is posted at ScholarlyCommons. https://repository.upenn.edu/be_papers/61

For more information, please contact repository@pobox.upenn.edu. 


\title{
LVAD as Destination Therapy - The Economic Dilemma
}

\begin{abstract}
The artificial heart, after decades of development, remains a long way off as a practical remedy for people with failing hearts. But a related technology, the left ventricular assist device (LVAD), has passed major milestones in its development and is poised for widespread use. This technology, which is an offshoot of the artificial heart program, may well have greater impact on society than the artificial heart. It is time to consider its probable costs to society. A heart transplant is the present treatment of choice for end-stage heart failure (ESHF).

Disciplines

Biomedical Engineering and Bioengineering

Comments

Copyright 2004 IEEE. Reprinted from IEEE Technology and Society Magazine, Volume 23, Issue 2, Summer 2004, pages 23-27.

This material is posted here with permission of the IEEE. Such permission of the IEEE does not in any way imply IEEE endorsement of any of the University of Pennsylvania's products or services. Internal or personal use of this material is permitted. However, permission to reprint/republish this material for advertising or promotional purposes or for creating new collective works for resale or redistribution must be obtained from the IEEE by writing to pubs-permissions@ieee.org. By choosing to view this document, you agree to all provisions of the copyright laws protecting it.
\end{abstract}




\section{LVAD as \\ Destination Therapy \\ The Economic Dilemma}

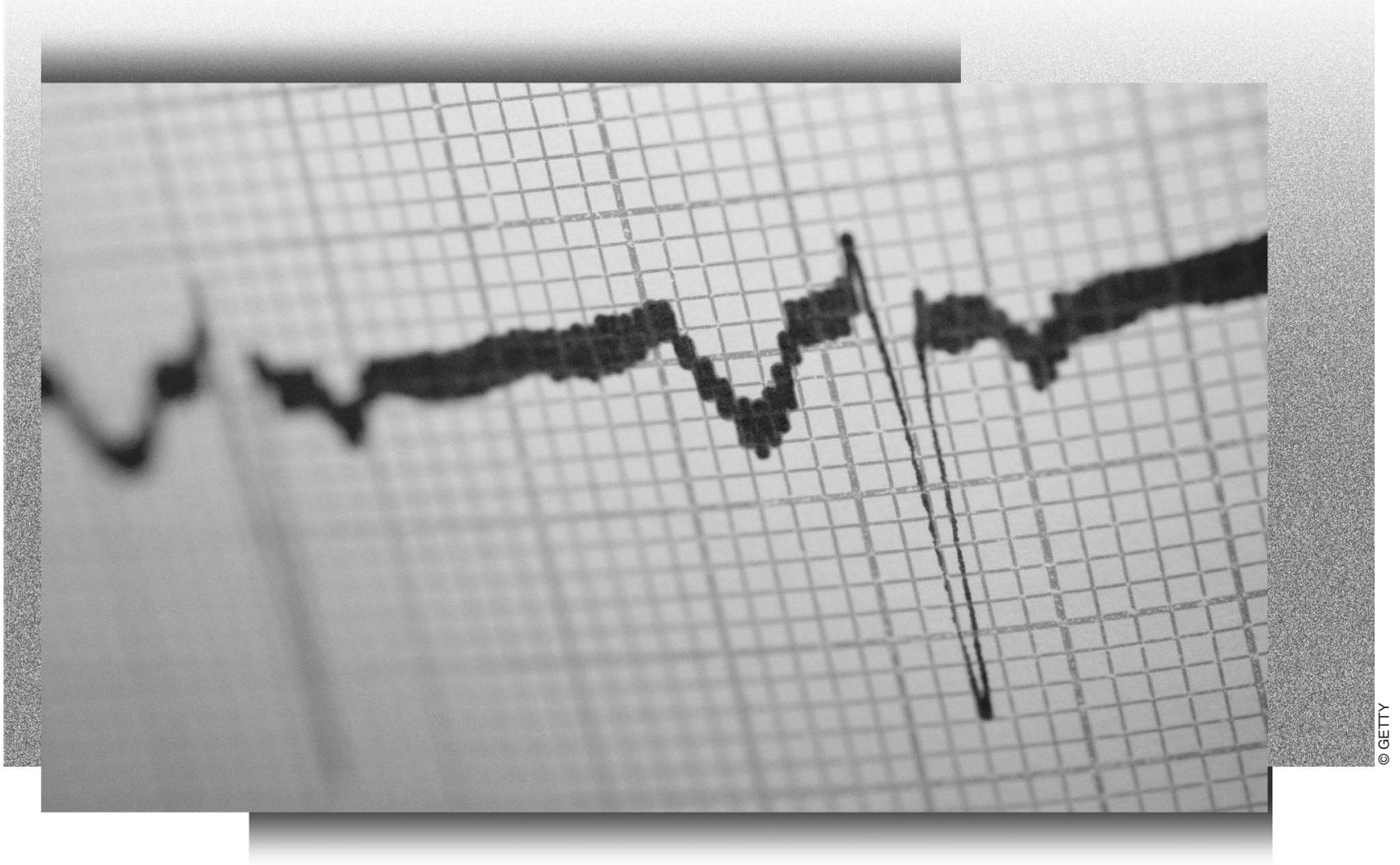

PAMELA DOUGLAS, COURTNEY MORGAN,

HEATHER LEE, AND KENNETH R. FOSTER

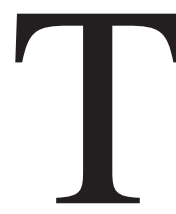

he artificial heart, after decades of development, remains a long way off as a practical remedy for people with failing hearts. But a related technology, the Left Ventricular Assist Device (LVAD), has passed major milestones in its development and is poised for widespread use. This technology, which is an offshoot of the artificial heart program, may well have greater impact on society than the artificial heart. It is time to consider its probable costs to society.

With about 550000 new cases and 1 million hospitalizations a year in the United States alone, congestive heart failure is a major health problem and a major cause of death among the elderly. The 4.7 million Americans with mild to severe heart failure face a five-year mortality rate of $50 \%$ [1]. Advanced heart failure, experienced by 250000 Americans, is a debilitating condition whose outcome for the patient is grim.

A heart transplant is the present treatment of choice for end-stage heart failure (ESHF). In part because of a lack of donors, only 3000 heart transplants are performed each year worldwide (two thirds of them in the 


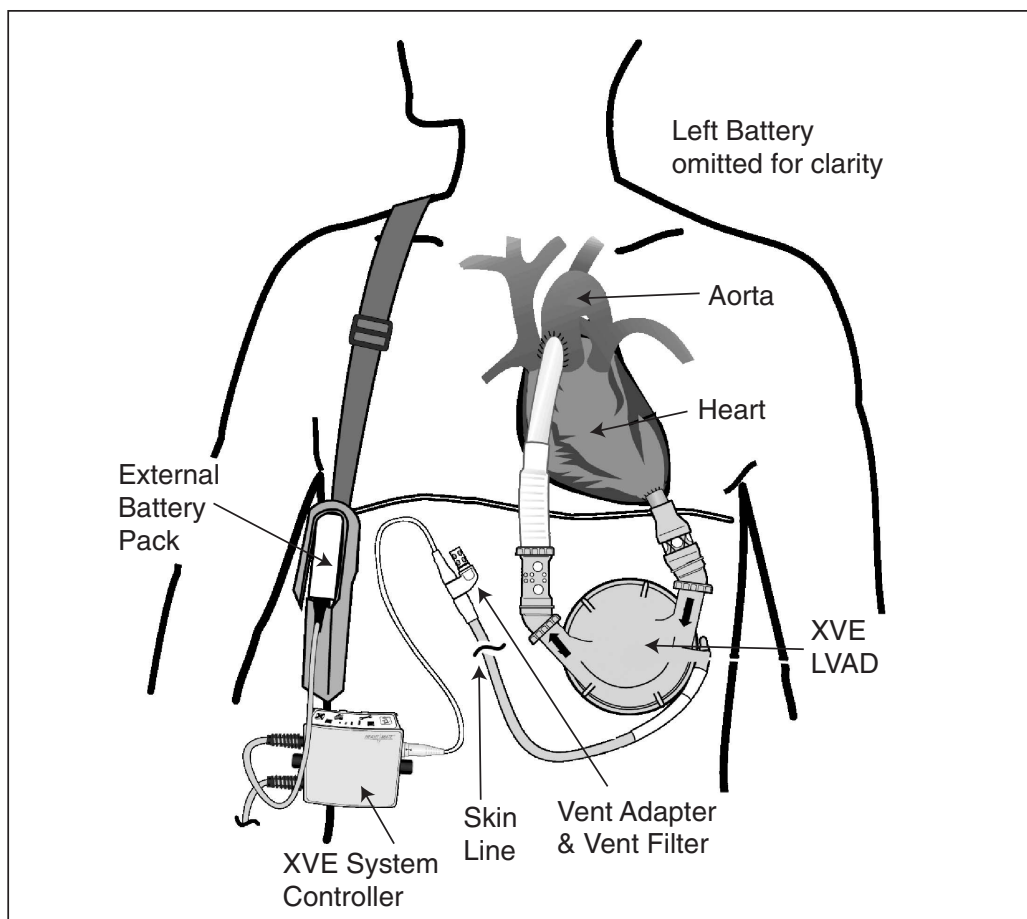

Fig. 1. Thoratec HeartMate ${ }^{\circledast}$ XVE left ventricular assist system. Reprinted with permission from Thoratec Corporation.

United States); 15000 patients are on waiting lists for transplants. Because of lack of donors, these numbers are not likely to increase substantially in the future.

\section{Enter the LVAD}

For many years, physicians have dreamed of replacing the failing heart with a mechanical pump. The most visible work along these lines has been the development of the total artificial heart (TAH), which was spurred by massive investments by the Artificial Heart Program, a U.S. program chartered in 1964 by the National Heart, Lung and Blood Institute (NHLBI), part of the National Institutes of Health.

As an offshoot of the artificial heart program, the NHLBI funded the development of ventricular support systems, which do not replace the heart entirely but assist it in pumping blood. The first ventricular support system was used in a human in 1963. Mechanical support systems, notably the Left Ventricular Assist Device (LVAD), came into frequent use in the 1980s as heart transplants became increasingly popular and the need arose to support the hearts of patients awaiting transplant.

LVADs typically bypass the left ventricle (which carries about $80 \%$ of the load of the heart) and pump blood directly into the aorta, from which it enters the systematic circulation. More recent systems also

\section{Only 3000 heart transplants are performed each year worldwide; 15000 patients are on waiting lists for transplants.}

assist the right ventricle (which pumps blood through the lungs) as well. The devices are either implanted entirely within the body with power lines and an air vent brought outside the body through the skin, or their pumps are located outside the body and connected to the heart and large blood vessels with tubes passing through the chest. Fig. 1 shows an LVAD of the first type, the HeartMate (Thoratec Corporation, Pleasanton CA).

\section{LVAD as Bridge to Transplant}

With the growing success of heart transplants, the need arose to sustain patients on a temporary basis until they could receive heart transplants, a role that the LVAD serves well. The FDA approved the first LVAD for use as "bridge to transplant" in 1994. At present, five different LVADs are on the market and several others are in advanced development stages. The FDA has never approved a TAH except for use in clinical trials.

By limiting approving of LVADs for sale as a bridge to transplant, the FDA restricted the device to a very small market consisting of, at most, a few thousand patients eligible for heart transplants, which is a small fraction of individuals suffering from end-stage heart failure. Consequently, medical device companies have undertaken studies to demonstrate the effectiveness of the LVAD for use in patients who are ineligible for a heart transplant because of old age, other serious illnesses, or simply residence too far from a hospital capable of performing heart transplants. For such patients the LVAD would be "destination therapy," just as a pacemaker is destination therapy for heart arrhythmias.

As destination therapy for end-stage heart failure, the safety and effectiveness of the LVAD would have to be compared to that of the presently accepted treatment using drugs. Important evidence came in 2001 
with the publication of a long-awaited study that was jointly sponsored by the NHLBI and the Thoratec Corporation [2]. This landmark study, known as the Randomized Evaluation of Mechanical Assistance for the Treatment of Congestive Heart Failure (REMATCH) study, compared the outcomes of 129 patients with end-stage heart failure who were ineligible for a heart transplant. Sixty-nine of these patients received a LVAD (HeartMate VE) and the other 61 were treated by drugs alone. The results were dramatic. The median survival time was 408 days in the device group and only 150 days in the medical-therapy group (Fig. 2).

There were, however, numerous serious complications from use of the LVAD (Table I). More than a quarter of the patients contracted serious infections from the device within three months after implantation, and by the end of two years more than one-third of the devices had failed [7]. However, only one patient with the LVAD died of left ventricular dysfunction, a cause of death in fifty of the control patients. Thus, despite its high failure rate and numerous complications, the LVAD increased the two-year survival rate of these very ill patients. Is this REMATCH success story convincing enough?

Apparently it was. On November 6, 2002, the FDA approved the HeartMate LVAD to "be implanted permanently in certain terminally ill patients who are not eligible for heart transplant." Noting the "serious side effects associated with the device," the FDA limited approval of the device for use with patients with severe ESHF. The Agency estimated that between 20000 and 30000 people a year could benefit from the device. The device has been marketed in Europe both as a bridge and an alternative to transplant since 1994.

There is, in fact, good reason to believe that the LVAD might benefit

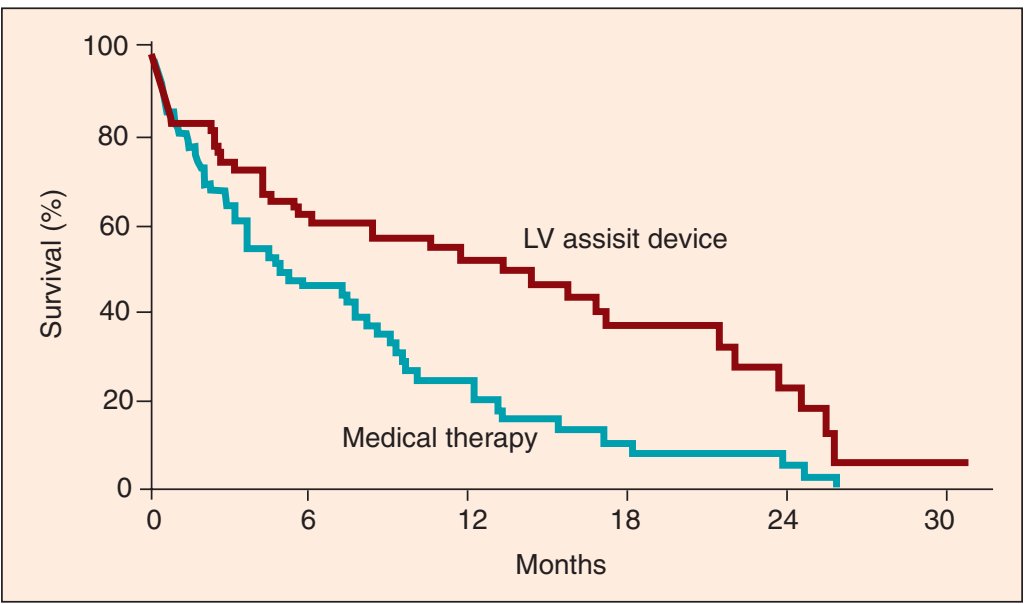

Fig. 2. Analysis of survival of patients in the REMATCH study [2]. Reprinted with permission.

a far larger patient population than those with ESHF, including patients after myocardial infarction, or suffering from postsurgical cardiac failure, acute myocarditis, or dilated cardiomyopathy. By "unloading" the heart, the LVAD reduces the pressures on the heart, providing a "bridge to recovery" [3]. Many of these patients can subsequently be

\section{The LVAD has been marketed in Europe both as a bridge and as an alternative to transplant since 1994.}

weaned from the LVAD. And also, by increasing cardiac output, the LVAD can lead to dramatic improvements in patients with heart failure, at least for the short term.

\section{How Much Will It Cost?}

Implantation of a LVAD, and associated medical care, is very expensive. Moskowitz et al. [4] reported that the first-year cost of LVAD implantation is presently $\$ 220000$, which includes $\$ 141000$ for the initial implant related hospitalization and \$67000 for the cost of the device. This is comparable to the cost of a heart transplant - and far more than drug therapy for heart failure. As the technology improves, the costs of the device will surely decline. But also, as the devices improve, the risk/benefit calculations of patients and their physicians will change, and their usage will increase.

By expanding the indications for use of the LVAD, the FDA will create a rapidly growing market for the devices. When FDA approval was limited to use as a bridge to transplant, the market for the device (at least in the United States) was limited to the number of patients eligible for heart transplants, which is in turn is limited by the availability of donors. Approval for marketing as destination therapy for ESHF patients who are not candidates for heart transplant greatly expanded its market. Any future approval for use with less severely ill patients as a bridge to recovery will result in further expansion.

Estimates for the ultimate size of the market for the LVAD in the 
United States vary considerably. Moskowitz et al. [4] projected that there will be 35000-75000 candidates for LVADs per year by 2020 . An investment firm recently predicted that the size of the American market for LVADs would be 100 000 units per year if the devices were approved as a "bridge to recovery" [5]. Indeed, the number of firms developing such devices is a measure of their optimism about the future growth of the market.

The aggregate costs of widespread usage of the LVAD could be staggering. At $\$ 220000$ per patient, a market of 100000 devices per year would correspond to an aggregate medical bill of $\$ 22 \mathrm{~B}$ per year in present dollars - just for the costs of implantation and first year care of the patients.

\begin{tabular}{lccc}
$\begin{array}{l}\text { TABLE I } \\
\text { Cause of Death } \\
\text { STUDY }\end{array}$ & $\begin{array}{c}\text { Medical Therapy } \\
\text { Group }\end{array}$ & $\begin{array}{c}\text { LVAD } \\
\text { Group } \\
\text { Number of Patients }\end{array}$ & Total \\
\hline Left ventricular dysfunction & 50 & 1 & 51 \\
\hline Sepsis & 1 & 17 & 18 \\
\hline Failure of LVAD & 0 & 7 & 7 \\
\hline
\end{tabular}

\begin{tabular}{lccc}
\hline $\begin{array}{l}\text { Miscellaneous } \\
\text { noncardiovascular causes }\end{array}$ & 0 & 5 & 5 \\
\hline Pulmonary embolism & 0 & 2 & 2 \\
\hline Acute myocardial infarction & 1 & 0 & 1 \\
\hline Cardiac procedure & 1 & 0 & 1 \\
\hline Perioperative bleeding & 0 & 1 & 1 \\
\hline Unknown & 0 & 2 & 2 \\
\hline Total & 54 & 41 & 95 \\
From [2]. Reprinted with permission. & & &
\end{tabular}

\section{Economic Dilemma}

The LVAD is a life-giving technology, but its aggregate costs to society could become daunting. Medicare has long covered LVAD therapy as bridge-totransplant. On November 19, 2003, the Centers for Medicare and Medicaid Services announced that Medicare will cover the cost of implantation of FDA-approved LVADs as destination therapy for patients who do not meet eligibility requirements for cardiac transplantation.
Dialysis provides a good example of the ability of a new technology to incur costs that far exceed original projections. In 1972 the U.S. Congress agreed to include dialysis for patients with end-stage renal disease in Medicare. The best projections at that time were that the program would serve $10 \quad 000$ patients, at a cost of $\$ 250 \mathrm{M}$ per year. Today, the program serves more than 20 times this number, at a cost (in present dollars) of $\$ 14 \mathrm{~B}$ per year. While the costs of dialysis (on a per-patient basis) declined in real terms, the demand for treatments far exceeded initial projections.

Government is thus faced with a dilemma. It is clearly unacceptable to deny patients a lifesaving treatment (such as dialysis or LVAD). But the aggregate costs of such treatments can potentially become

issue is fundamentally one of justice: what does a just society provide to its members according to what priorities?

This conflict appeared, for example in 1987, when the Oregon legislature voted to discontinue its Medicaid organ transplant coverage for an estimated 34 recipients over 2 years at an estimated cost of 2.2 million dollars to provide basic health care for approximately 1500 lowincome children and pregnant women. Then governor, Neil Goldschmidt, stated when he signed the bill into law, "How can we spend every nickel in support of a few people when thousands never see a doctor or eat a decent meal?"

This dilemma is also seen in the 41 million American citizens who lack health insurance, and receive basic health services on a hit-ormiss basis (if at all). Government has been unable to extend health insurance to these people. One notable attempt was in President Clinton's unsuccessful campaign for health care reform early in his Presidency. Clinton's plan foundered in part because middleclass Americans feared that universal health coverage would mean, for them, loss of coverage for high-tech medical services. "Because the middle classes will not tolerate restrictions on access to [medical] technologies," historian David Rothman pointed out [7], "the lower classes are left to fend for themselves."

A recent estimate of the costs of extending health insurance to all Americans was provided in a 2003 plan proposed by the Commonwealth Fund (a New York foundation), which was projected to cost the federal government \$70B [8]. Given the present economic climate, the prospects of such a plan are very dim indeed. With the LVAD, the camel's nose is already under the tent, and U.S. federal and state governments could easily incur annual costs of tens of billions of dollars in coming years. This may be a good example of the "collision 
course" that Callahan describes. But the collision is indirect: by pushing up costs of health care, the LVAD (and other expensive technologies) will make it even harder to extend health insurance to all Americans.

Other countries take a different approach. England restricts consumption of high-tech medical services by, in effect, rationing medical care (except for those with the ability to pay for private care). But these countries are also facing the prospect of unsustainable medical costs. Can even wealthy societies afford the splendid technology of modern medicine?

The LVAD is truly a splendid technology, a product of the artificial heart program developed without the hoopla that accompanied the artificial heart. But it creates a dilemma that will also arise with other artificial organs that may be developed in the future: the treatment costs are very high, there are many potential users, and the availability of the devices (unlike those of organs for transplant) is essentially unlimited. To paraphrase Callahan's question: at what point does a new medical technology become too much of a good thing?

\section{Author Information}

The authors are with the Department of Bioengineering, University of Pennsylvania, Philadelphia, PA, 19104; Email contact: kfoster@ seas.upenn.edu.

\section{References}

[1] W. B. Kannel et al., "Changing epidemiological features of cardiac failure," Br. Heart J., vol. 72, Suppl. 2, pp. S3-9, 1994.

[2 ] E. A. Rose et al., "Long-term mechanical left ventricular assistance for end-stage heart failure," N. Engl. J. Med., vol. 345, no. 20, pp. 1435-1443, 2001.

[3] R. Hetzer, J. H. Müller, Y-G Weng, R. Meyer, and M. Dandel, "Bridging-to-recovery," Ann. Thorac. Surg., vol. 71, Suppl. 1, p. S109S113, 2001.

[4] A.J. Moskowitz, E.A. Rose, and A.C. Gelijns, "The cost of long-term LVAD implantation," Ann. Thorac. Surg., vol. 71, Suppl. 3, pp. S195-8, 2001.

[5] W. Morgan, "Securities analysis of Thoratec," Rep., Jan. 15, 2002. Available on the Internet at einvestmentbank.com/research/ 011502thor.pdf

[6] D. Callahan, "Too much of a good thing: How splendid technologies can go wrong," Hastings Center Rep., vol. 33, no. 2, pp. 19-22, 2003.

[7] D.J. Rothman, Beginnings Count. New York, NY: Oxford Univ. Press 1997.

[8] K. Davis and C. Schoen, "Creating consensus on coverage choices," The Commonwealth Fund, New York, NY, 2003. Available on the Internet at http://www.healthaffairs.org/WebExclusives/ 2203Davis.pdf

\section{LETTERS (continued from page 5)}

\section{Reply by Chester Smith}

I agree with Mr. Avishay Gordon that the term "guerilla" is not exactly what we need to describe international activists who have resorted to terrorism from time to time. Actually the Al-Qaeda people have targeted the overthrow of the Saudi Royal family and they do, indeed, have in-country activity with that objective in view. In that sense they might be classifed as "guerillas," but their operations in the international scene exceed the classic narrow definition normally used.

We do not have a clear idea of what motivates these people and our present administration seems to have no interest in finding out. Simply labeling them "bad guys" is not helpful. American interest in the Middle East is primarily economic. "Terrorist" action is an attention getter and in some ways resembles a call for third-party nations to "back off." The apparently religio-political agenda takes these organizations out of the pure terrorism-for-its-own-sake category. At the moment we do not have a properly descriptive term for them. Perhaps Mr Gordon can suggest one.

Under the restricted definition Mr Gordon proposes, the Palestinian suicide people qualify as guerilla fighters not terrorists on the basis of motivation and not method.
Clearly their objective is to reclaim their land from what appears to them to be an occupation by a non-Asiatic (e.g., European/American) culture that was imposed during the first half of the twentieth century. There is no solution to that situation that fails to recognize the essential religio-cultural character of the conflict.

"Terrorism" as such relies on the dramatic and may be entirely idiosycratic as in the Timothy McVey case and the Oklahoma Federal Building episode. Al Qaeda and other similar groups appear to have definite objectives in view and may or may not use terrorism to accomplish them. If nothing else works, give your opponent a bloody a nose.

The intent of the original piece was to show the incredible efficiency of this type of activity in terms of results versus investment. Evidently there is no quarrel with that premise. My thanks to Mr Gordon. It is nice to know that somebody actually read the article and thought enough to critique the terminology.

Chester L. Smith Bedford, MA U.S.A. Clsmith82@comcast.net 